\title{
A Psychrometric Approach to Schedule Irrigation
}

\author{
Modesto Capiel
}

INTRODUCTION

To schedule crop irrigation properly, the weather must be considered together with the soil and the plant water status. The irrigation needs of crops, however, are generally assessed unilaterally, either from the standpoint of the soil, the weather, or the plant. Such assessment can lead to inaccurate estimates of the irrigation interval which in turn influences crop growth, photosynthetic activity, differentiation processes, and ultimately the yield and quality of the crop.

It has been found that photosynthesis in plants may be reduced even very shortly after an irrigation as a result of internal water deficits arising from the lag of absorption behind transpiration under high evaporative demands (4). ${ }^{2}$ Conversely, it is well known that plants may regain turgidity temporarily in spite of the fact that the soil is close to the so-called permanent wilting point. These extremes simply are the result of atmosphere and soil interactions on the diffusive resistances to water flow along the transpiration stream. Shaw and Laing (B) indicate that the soil water potential and the atmospheric evaporative demands must be known, because of their obvious interactions, to define a moisture stress in plants.

Irrigation schedules generally have relied on regimes based on predetermined soil water suction limits, or on empirical or semi-rational calculations of the accumulated evapotranspiration. More elastic irrigation schedules should be depended on, so that a crop can take advantage of an otherwise inclement or harsh weather, such as one prevailing on clear hot days when photosynthesis proceeds at an optimum rate.

Leaf turgidity has been used recently as an approach to the recognition of irrigation needs. Ehlig (1) discussed the thermocouple psychrometer method to determine the DPD and OP of plants. Mederski (2) developed another method for determining the internal water status or relative turgidity of certain plants by beta ray gauging.

The technique selected for this preliminary evaluation is directed to provide a means by which it may be possible to evaluate irrigation needs on the basis of the simultaneous appraisal of the evaporative demands of the atmosphere and the free energy of water at the soil surface. The method lends itself to judge its application with greater or less intensity with

1 Associate Soil Scientiat, Agricultural Experiment Station, Mayagüez Campus, University of Puerto Rico, Río Piedras, P. R.

2 Numbers in parentheses refer to Literature Cited, p. 630. 
regard to irrigation frequency. It would depend on the crop habits and its stage of growth-whether vegetative or reproductive. Essentially, the method consists in recording the difference in evaporative cooling between a nonventilated wet bulb thermojunction at the height of the crop canopy and an increasingly less intesnive evaporative cooling at the soil surface, as evaporation proceeds and the free energy of soil water decreases. Thus, by taking advantage of the thermocouple principle a curve can be obtained in a microvolt recorder which gets steeper as the evaporative demands increase and the plants get farther away from the zero time of a given irrigation.

The data presented and analyzed below is based on a statistical evaluation of a laboratory study of the free energy-evaporative demands relationships, using the technique mentioned.

\section{MATERIALS AND METHODS}

A cylindrical plug $3.5 \mathrm{~cm}$. long and $2.25 \mathrm{~cm}$. in diameter was molded to encase a thermocouple "hot" junction such that the leads (No. 30 wire) would extend along the plug and exit through its lower flat surface. The junction was located to nearly contact the upper flat surface but was not exposed. The "cold" junction acted as a wet bulb (nonventilated) by enclosing it in a wick connected on one end to a distilled water reservoir (fig. 1).

The "hot" junction plug was maintained surrounded with one-half $\mathrm{cm}$. of sand and encased in a plastic cylindrical box with the flat upper surface of the plug exposed to the air. The "cold" junction (wet bulb) was maintained about $30 \mathrm{~cm}$. above the exposed surface of the plug. The terminals of both junctions were connected to a microvolt recorder, adjusted to 500 microvolts full scale (allowing up to $50 \mu \mathrm{V}$. for any negative values in the chart).

The plug before recording was wetted to saturation by capillarity, together with a replicate plug made to estimate the moisture percent by weight of the plug at any moment. This obviated the need to disconnect the other plug from the recording system. A direct reading balance, sensitive to $1.0 \mathrm{mg}$., was used for this purpose. The data includes two drying cycles of the "hot" junction plug.

The recording system was maintained in an air conditioned room, the air conditioning system being kept alternately on and off to permit varying degrees of vapor pressure deficit. A continuous recording of the air temperature and the relative humidity was obtained with a hygrothermograph, so that the mean saturation vapor pressure deficit $\left(e_{d}\right)$ for any given time interval could be obtained by the equation:

$$
e_{d}=e_{s}-e_{s}(\mathrm{RH})
$$


where $e_{s}$ is the saturated vapor pressure at the air temperature, obtained from vapor pressure tables, and $R H$ is relative humidity.

The wind movement was maintained nearly constant and insignificant throughout the course of the experiment. Direct solar radiation was never

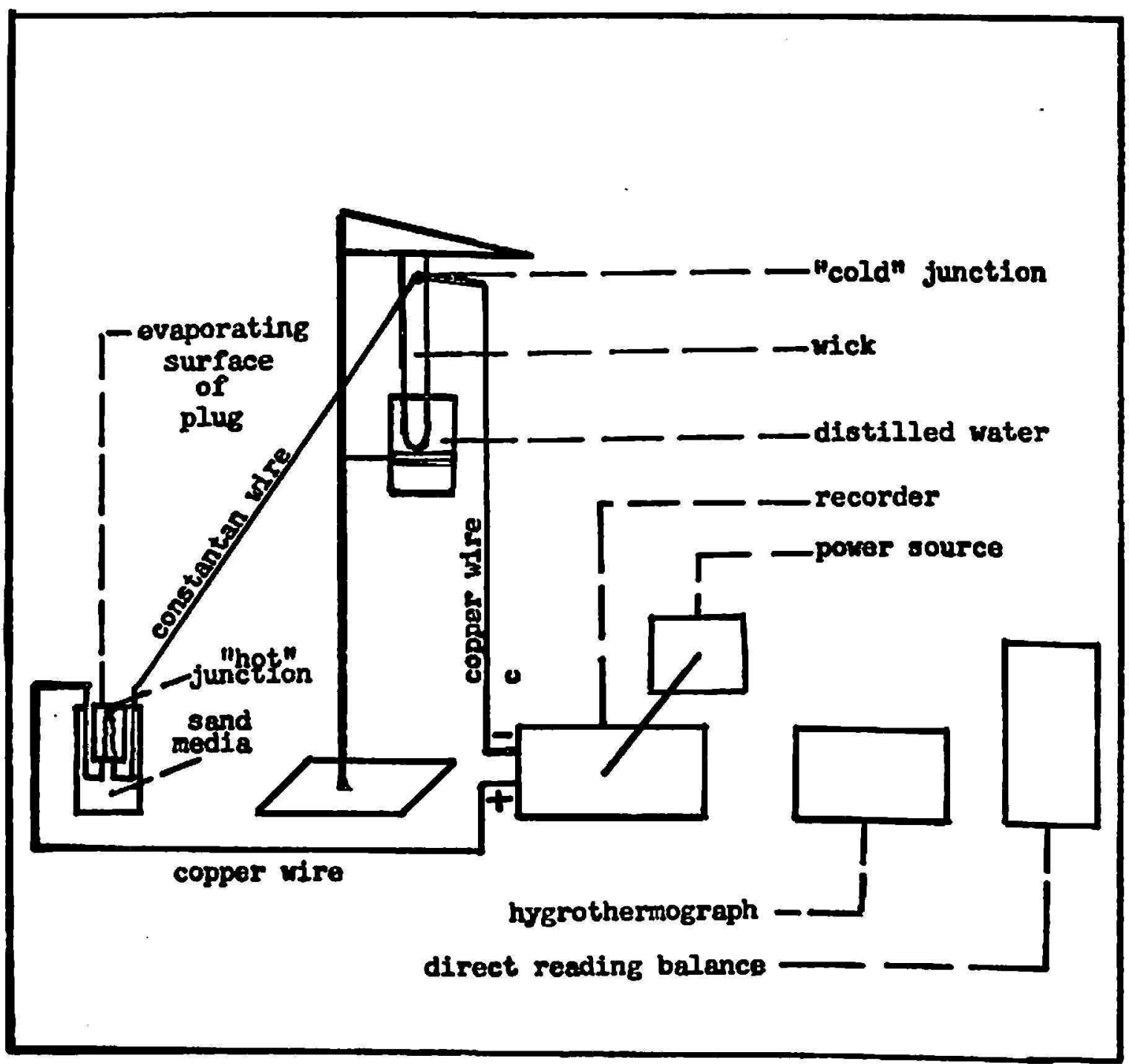

Fre. 1. Diagram of the laboratory apparatus.

allowed into the room, and a 40-watt light bulb was kept on during the night.

\section{RESULTS AND DISCUSSION}

The mean values of the recorded differential temperature $(\Delta t)$, as well as the corresponding means of air saturation deficit $\left(e_{d}\right)$, evaporation rate from the plug matrix $\left(e_{m}\right)$, and its moisture content $(\theta)$, are shown in table 1. They were averaged for successive short-time intervals along two drying cycles of the plug. 
TABLE 1.-Mean values of differential temperalure $(\Delta t)$ and the corresponding mean values of saluration deficit $\left(e_{d}\right)$ of the atmosphere, and of evaporation rate $\left(e_{m}\right)$ and moisture percent $(\theta)$

of the matrix material

\begin{tabular}{|c|c|c|c|}
\hline $\begin{array}{l}\text { Differential temperature } \\
\Delta l\end{array}$ & Saturation deficit ed & Evaporation rate $e_{m}$ & Moisture $\theta$ \\
\hline Microvolts/hour & Millibars & Grams/hour & Percent \\
\hline 108 & 11.80 & 0.096 & 29.78 \\
\hline 60 & 10.05 & .031 & 28.40 \\
\hline 120 & 13.90 & .080 & 27.39 \\
\hline 78 & 10.40 & .048 & 25.49 \\
\hline 95 & 0.45 & .071 & 23.88 \\
\hline 58 & 8.23 & .031 & 23.02 \\
\hline 208 & 15.27 & .130 & 21.83 \\
\hline 101 & 13.29 & .065 & 18.02 \\
\hline 144 & 12.75 & .101 & 14.18 \\
\hline 119 & 14.46 & .061 & 10.60 \\
\hline 158 & 12.45 & .065 & 7.23 \\
\hline 123 & 12.30 & .043 & 6.03 \\
\hline 282 & 24.46 & .060 & 4.91 \\
\hline 275 & 17.83 & .046 & 4.16 \\
\hline 169 & 15.18 & .027 & 3.03 \\
\hline 244 & 12.97 & .035 & 2.10 \\
\hline 98 & 9.17 & .071 & 30.12 \\
\hline 176 & 13.43 & .149 & 29.32 \\
\hline 125 & 16.81 & .093 & 28.35 \\
\hline 212 & 15.73 & .150 & 27.45 \\
\hline 121 & 13.34 & .059 & 26.46 \\
\hline 114 & 10.70 & .065 & 25.64 \\
\hline 102 & 9.23 & .056 & 25.04 \\
\hline 108 & 9.45 & .064 & 24.61 \\
\hline 96 & 8.36 & .056 & 23.32 \\
\hline 81 & 6.65 & .042 & 21.90 \\
\hline 177 & 12.77 & .112 & 20.88 \\
\hline 35 & 6.81 & .027 & 20.17 \\
\hline 87 & 8.60 & .052 & 19.87 \\
\hline 137 & 13.55 & .074 & 19.39 \\
\hline 245 & 17.19 & .130 & 18.74 \\
\hline 127 & 15.97 & .055 & 18.12 \\
\hline 129 & 12.50 & .050 & 17.66 \\
\hline 95 & 8.78 & .047 & 16.32 \\
\hline
\end{tabular}

${ }^{1}$ Each mean value was calculated from subsequent intervals of two drying cycles of the plug.

Simple linear regression analyses of the data on table 1 appear to indicate that $\Delta t$ correlates best with the air parameter $e_{d}(r=.81)$. The plug matrix parameters, $e_{m}$ and $\theta$, correlated much less significantly with $\Delta t$ $(r=.42$ and .51$)$ and less so with each other $(r=.37)$. 
By organizing the data in table 1 into low, medium and high ranges of air and plug moisture $\left(e_{d}\right.$ and $\theta$ ) a higher coefficient of correlation was obtained between the evaporation rate of the plug matrix $\left(e_{m}\right)$ and $\Delta t$ than with the saturation deficit ( $\left.e_{d}\right)$ (table 2). At the low level of plug moisture $(\theta) e_{m}$ is poorly related to $\Delta t$. However, $e_{d}$ was significantly related to $\Delta t$ at all levels of $\theta$. It may also be observed from table 2 that, in general, $\Delta t$ exhibits better correlations with the individual parameters when ordering the data by levels of moisture content of the plug matrix than by levels of saturation deficit of the air $\left(e_{d}\right)$. The fact that $e_{m}$ correlates more significantly

TABLE 2.-Statistical data related to the simple linear regression of the differential temperalure $(\Delta t)$ on the evaporation rate $\left(e_{m}\right)$ and the moisture content $(\theta)$ of the matrix malerial (plug), and on the saturation deficit $\left(e_{d}\right)$ of the air

\begin{tabular}{|c|c|c|c|c|}
\hline Correlated variables & Matrix $\theta$ & $e_{d}$ & $\begin{array}{l}\text { Correlation } \\
\text { coefficient }\end{array}$ & $\begin{array}{l}\text { Standard error } \\
\text { of estimate }\end{array}$ \\
\hline & Range & Range & $r$ & $s_{0}$ \\
\hline$\Delta t$ vs. $\epsilon_{m}$ & & low & $.88^{* *}$ & 11.13 \\
\hline$\Delta l v s . e_{m}$ & & medium & .03 & 45.37 \\
\hline$\Delta t v s . e_{m}$ & & high & .17 & 66.13 \\
\hline$\Delta l$ vs. $e_{m}$ & low & & .18 & 73.97 \\
\hline$\Delta t$ vs. $c_{m}$ & medium & & $.94^{* *}$ & 20.84 \\
\hline$\Delta t$ vs. $e_{m}$ & high & & $.93^{* *}$ & 15.72 \\
\hline \multirow[t]{3}{*}{$\Delta t$ vs. $\theta$} & & low & .17 & 23.13 \\
\hline & & medium & .43 & 41.05 \\
\hline & & high & .45 & 60.02 \\
\hline$\Delta l$ vs. $e_{d}$ & low & & $.78^{*}$ & 47.11 \\
\hline$\Delta t$ es. $e_{d}$ & medium & & $.85^{* *}$ & 32.90 \\
\hline$\Delta t v s . c_{d}$ & high & & $.68^{*}$ & 31.36 \\
\hline
\end{tabular}

* Significant at the 5-percent level.

** Significant at the 1-percent level.

with $\Delta t$ than $e_{d}$, exhibiting the lowest standard error of estimate (table 2), suggests an interaction among the parameters $e_{d}, e_{m}$, and $\theta$.

The linear, multiple regression equation

$$
\Delta t=55.27+808.39 e_{m}+7.60 e_{d}-3.60 \theta
$$

with all the terms expressed in the dimensions given in table 1 , accounts for 81 percent of the variations in $\Delta t, 15$ percent more than that accounted for by $e_{d}$ alone. The $t$ values associated with the partial regression coefficients of equation (1) are significant at the 1-percent level, suggesting a high interaction between the three factors. The correlation coefficier.t $(R)$ of this equation is 0.90 , which is significant at the 1-percent level.

Although either $e_{m}$ and $\theta$ correlated less significantly by simple linear 
regression with $\Delta t$ than $e_{d}$, by multiple regression they contributed as much as $e_{d}$ alone in predicting $\Delta t$. Both accounted for 70 percent of the variations in $\Delta t$. The $t$ values associated to their partial regression coefficients are significant at the 1-percent level. The equation is not presented, however, because equation (1) explained a higher proportion of the sum of squares of $\Delta t$. The results of this analysis are mentioned here only to show that the mean recorded differential temperature (or potential) depends on the interactions between $e_{d}, e_{m}$ and $\theta$. When either $e_{m}$ or $\theta$ are included with $e_{d}$ in a similar regression analysis, the multiple correlation coefficient is not higher than for $\Delta t=f\left(e_{m}, \theta\right)$. As a matter of fact, the standard errors of estimate resulting from the regression of $\Delta t$ on any combination of the three factors $\left(e_{d}, e_{m}\right.$, and $\left.\theta\right)$ are quite similar to each other. They have a mean value of $34.83 \mu \mathrm{V}$. with a standard deviation of only $0.64 \mu \mathrm{V}$.

Certain limitations are imposed upon a laboratory study of this kind which cannot be neglected when evaluating the results. The vertical distance (about $30 \mathrm{~cm}$.) maintained between the "hot" and the "cold" junctions permitted a gradual stratification of the microclimate in the experimental set up. Certain wind, air humidity, and solar radiation pockets below the crop canopy may exist under field conditions causing non-homogenous conditions of the microclimatic pattern in time and space. These isolated discontinuities may influence the $e_{m}$ of the plug matrix and its nearby surrounding soil. This condition of course can be compared to the variability encountered in gravimetric determinations, resistance blocks, and tensiometers. Differences in root activity and conditions of drainage obviously add to such variability.

\section{SUMMARY}

A laboratory evaluation was directed to provide a means for assessing the need for irrigation based on the simultaneous appraisal of the evaporative demands of the atmosphere and the free energy of water at the soil surface.

The method essentially consists in recording the difference in evaporative cooling between a non-ventilated wet bulb thermojunction at the height of a crop canopy and less intensive evaporative cooling at the soil surface, as evaporation proceeds and the free energy of soil water decreases. Utilizing the principle of the thermocouple, a curve is obtained in a microvolt recorder which gets steeper as the evaporative demands increase and the plant gets farther away from the zero time of a given irrigation.

Statistical data are presented which indicates that the continuously recorded yotential $(\Delta t)$ is a major function of evaporative demands of the air $\left(e_{d}\right)$, of the moisture content of the matrix material $(\theta)$, and of jts evaporation rate $\left(e_{m}\right)$. 


\section{RESUMEN}

Se realizó un estudio de laboratorio para evaluar objetivamente las necesidades de riego, considerando simultáneamente las exigencias de evaporación de agua de la atmósfera y el potencial del agua en el suelo.

Esencialmente, el método consiste en llevar un récord continuo de la diferencia en enfriamiento entre una superficie húmeda a la altura de la cosecha y otra superficie (el suelo) en la que la evaporación disminuye a medida que la humedad se agota. Asi que, utilizando el principio termoeléctrico se registra una curva potenciométrica cuyo valor aumenta al ritmo de la exigencia de evaporacion de agua evaporación del aire y a medida que pasa el tiempo después de un riego determinado.

Los datos obtenidos, una vez analizados estatísticamente, tienden a indicar que el potencial registrado continuamente $(\Delta t)$ es mayormente una función de lo que exige la atmósfera en forma de evaporación $\left(e_{d}\right)$ del contenido de humedad de la matrix $(\theta)$ y de su tasa de evaporación $\left(e_{m}\right)$.

\section{LITERATURE CITED}

1. Ehlig, C. F., and Gardner, W. R., Relationship between transpiration and the internal water relations of plants, Agron. J. 56: 127-30, 1964.

2. Mederski, H. J., Determination of the internal water status of plants by beta ray gauging, Soil Sci. 92(2): 143-6, 1961.

3. Shaw, R. H., and Laing, D. R., Plant Environment and Efficient Water Use. Symposium on plant environment and efficient water use. Amer. Soc. Agron. and Soil Sci. Soc. Amer., Madison, Wisc., 1966.

4. Slatyer, R. O., Plant-Water Relationships, Academic Press, London and New York, 1967. 